\title{
Focus on Research
}

\author{
Deutsches Ärzteblatt Can Look Back on a Long Tradition of Publishing Original \\ Articles in Medical Science
}

Svenja Ludwig, Christopher Baethge

$\mathbf{T}$ he readers of Deutsches Ärzteblatt take it for granted that our journal contains original scientific reports. Nowadays, that is. For many decades, Deutsches Ärzteblatt was a purely political organ of physicians in Germany, and it was only in the 1950s that it began regularly printing articles of an educational nature by scientific authors. In the meantime, carefully checked review articles and continuing medical education (CME) articles have become one of the hallmarks of Deutsches Ärzteblatt. But what about original articles, i.e., initial publications of scientific research findings?

The term "original article" comprises a number of subvarieties originating in different fields of medical science. Reports of experimental studies are among the most common types (basic research: laboratory investigations, animal experiments); epidemiological research includes cohort studies, case-control studies, and cross-

\section{TABLE}

Types of study among original articles published in Deutsches Ärzteblatt from 1958 to 2009

\begin{tabular}{l|r}
\hline Type of study & Number \\
\hline Case series & 444 \\
\hline Cohort study & 59 \\
\hline Cross-sectional study & 45 \\
\hline Description of registry data & 27 \\
\hline Case-control study & 26 \\
\hline Single case report & 18 \\
\hline Non-randomized, controlled study & 16 \\
\hline Secondary data analysis & 15 \\
\hline Experimental study on animals or cells & 14 \\
\hline Randomized controlled study & 12 \\
\hline Method development & 3 \\
\hline Monitoring & 2 \\
\hline Genetic study & 1 \\
\hline Other & 15 \\
\hline Total & 697 \\
\hline
\end{tabular}

sectional studies. Finally, clinical research includes, among other types of study, case reports, open observational studies, and the gold standard of research in clinical medicine-randomized clinical trials.

This short overview is intended to document the presence and distribution of these types of original articles in Deutsches Ärzteblatt since the introduction of the medical-scientific section of the journal, i.e., the section that currently appears under the heading "Medicine."

The purpose of this analysis is not just to satisfy our own curiosity, but to identify some important clinical studies that are not yet represented in databases such as Medline. As early as 1995, Egger and Smith (1) pointed out that many clinical studies are published in journals that are not represented in the international bibliographical databases-a problem that can lead to distorted conclusions in reviews and meta-analyses. Deutsches Ärzteblatt has only recently found its way into international databases such as Medline and Embase: Its scientific articles have appeared in Medline only from 2008 onward. Thus, all articles published in Deutsches Ärzteblatt before 2008 cannot be retrieved by a Medline search, which is the usual means of searching for articles on any medical topic. Yet some important articles were, of course, published in Deutsches Ärzteblatt before 2008.

Broad-based analyses of articles in other publications (2) have led to the rescue of many controlled studies from oblivion. As a consequence, many that are not retrievable on Medline can now be found in the Cochrane Controlled Trials Register, a database that has become an important source of review articles.

\section{Half a century}

This retrospective analysis includes a total of 697 original articles that were published from 1958 to 2009. All of these studies were categorized into study types in accordance with the classifications of the German Cochrane Center and of Blettner et al. (3, 4). Most of them involved clinical research, mainly single-case reports and case series. There were, however, 28 controlled studies in the group, including 12 randomized, controlled studies.

A tally of all of the manuscripts yielded the following totals: 444 case series, 59 cohort studies, 45 cross-sectional studies, 27 descriptions of registry data, 
FIGURE 1

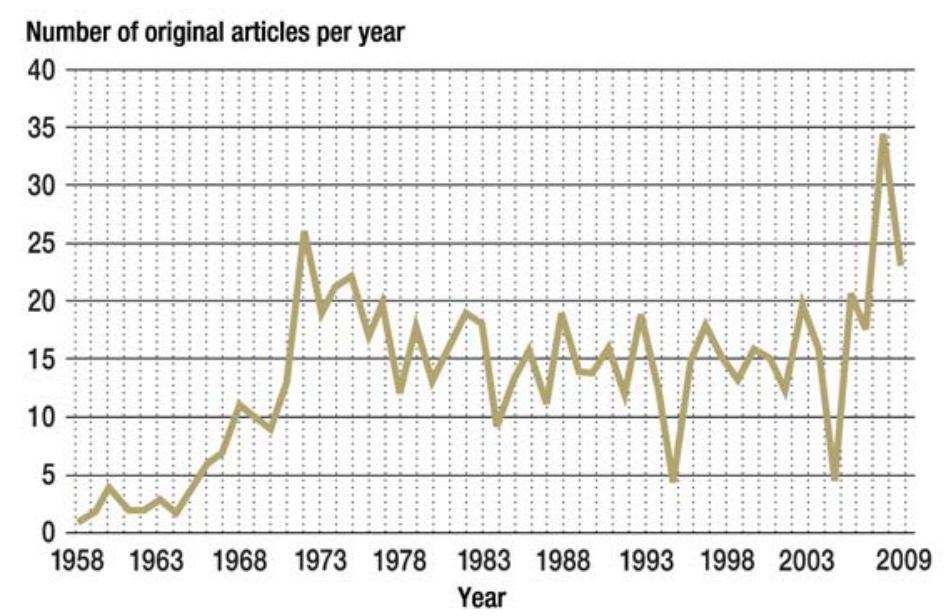

FIGURE 2

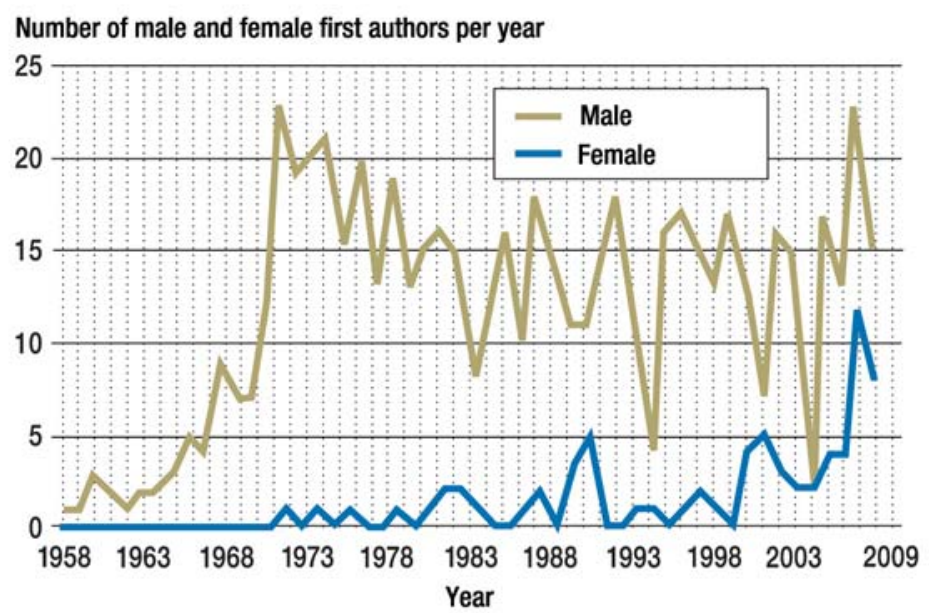

26 case-control studies, 18 single-case reports, 16 non-randomized controlled studies, 15 secondary data analyses, 14 experimental studies on animals or cells, 12 randomized controlled studies, 3 reports of newly developed methods, 2 reports of monitoring, and a single genetic study. The remaining articles (classified as "Other") included systematic literature reviews, clinical guidelines, descriptions of biometric methods, and a practical recommendation (Table).

Over half a century of observation from 1958 to 2009, the number of original articles appearing in Deutsches Ärzteblatt increased, albeit with marked fluctuations in between (Figure 1): after a slow start, a rise became noticeable from the early 1970's onward. Although the number of pages in the "Medicine" section of each issue has remained constant right up to the present, about 15 original articles were published each year starting in the early 1970's, with another marked rise in recent times. 2008 saw the publication of 34 original articles, the largest number in a single year to date. Over the last 10 years, the number of case series in Deutsches Ärzteblatt has declined, while that of cross-sectional and controlled studies is on the rise.

\section{Surgical and non-surgical fields}

Most of the original articles were from three fields: surgery, internal medicine, and gynecology. More articles originated from the surgical disciplines than from the non-surgical ones, with 157 and 73 publications in surgery and gynecology (the two best represented surgical fields), respectively. This is surprising, in view of the fact that the non-surgical fields accounted for about $80 \%$ of all the reviews and original articles published in Deutsches Ärzteblatt from 1965 onward (5).

The number of authors per article increased dramatically, as has also been found in studies of other journals (6): The number first grew at a leisurely pace, up to an average of 2.2 authors per article in 1994, then rose steadily to reach 3.4 in 2006 and 6.5 in 2009. As for the percentage of women among first authors, the figure of $10 \%$ for the entire period from 1958 to 2009 confirms the well-known underrepresentation of women (7). There has been recent improvement, however, with women accounting for a little over one-third of all first authors in the last two years (Figure 2).

The Medical-Scientific Editorial Office of Deutsches Ärzteblatt is happy to receive original articles in the fields of clinical research and health services research and to sustain the role of our journal as an organ for the publication of research findings. Publishing in Deutsches Ärzteblatt has also become significicantly more attractive to authors in recent years, for a number of reasons: indexing in Medline and all other important medical databases, complete translation of all scientific articles into English for publication in our Englishlanguage online journal (Deutsches Ärzteblatt International), open access on the Internet to both the German and the English versions, and the authors' honorarium. Also, Deutsches Ärzteblatt will receive an impact factor in the near future.

\section{Conflict of interest statement}

Dr. Svenja Ludwig is a production editor in the science and medical section of Deutsches Ärzteblatt and PD Dr. Christopher Baethge is Chief Scientific Editor of Deutsches Ärzteblatt and Deutsches Ärzteblatt International.

\section{REFERENCES}

1. Egger M, Smith DS: Misleading meta-analysis. BMJ 1995; 310: $752-4$.

2. Blümle A, Antes G: Handsuche nach randomisierten kontrollierten Studien in deutschen medizinischen Zeitschriften. Dtsch Med Wochenschr 2008; 133: 230-4.

3. Prel JB du, Röhrig B, Blettner M: Critical appraisal of scientific articles-Part 1 of a series on evaluation of scientific publications [Kritisches Lesen wissenschaftlicher Artikel: Teil 1 der 
Serie zur Bewertung wissenschaftlicher Publikationen]. Dtsch Arztebl Int 2009; 106(7): 100-5.

4. Röhrig B, Prel JB du, Blettner M: Study Design in Medical Research-Part 2 of a series on evaluation of scientific publications [Studiendesign in der medizinischen Forschung: Teil 2 der Serie zur Bewertung wissenschaftlicher Publikationen]. Dtsch Arztebl Int 2009; 106(11): 184-9.

5. Eckhardt, Tobias-Michael: Fünfzig Jahre MedizinischWissenschaftlicher Teil im Deutschen Ärzteblatt. InauguralDissertation zur Erlangung der Doktorwürde der Hohen Medizinischen Fakultät der Universität zu Köln, 24. Februar 2010.

6. Baethge C: Publish together or perish [Gemeinsam veröffentlichen oder untergehen]: Dtsch Arztebl Int 2008; 105(20): 380-3.

7. Baethge C: First authors in Deutsches Ärzteblatt: women are catching up [Forscherinnen werden forscher]: Dtsch Arztebl Int 2008; 105(28-29): 507-9.

\section{Corresponding author}

Dr. med. Svenja Ludwig

Production Editor, Science and Medical Section

ludwig@aerzteblatt.de

Translated from the original German by Ethan Taub, M.D.

Gite this as: Dtsch Arztebl Int 2010; 107(18): 317-9 DOL: 10.3238/arztebl.2010.0317 